\title{
The Epidemiology of Children's Team Sports Injuries
}

\section{An Important Area of Medicine and Sport Science Research}

\author{
Nicola Maffulli ${ }^{\mathrm{a}}$, Dennis Caine \\ ${ }^{a}$ Keele University School of Medicine, University Hospital of North Staffordshire \\ and Hartshill Orthopedic Surgical Unit, Stoke on Trent, Staffordshire, England; \\ bepartment of Physical Education, Health and Recreation, Western Washington \\ University, Bellingham, Wash., USA
}

\section{Introduction}

Participation in children's and youth sports is increasingly popular and widespread in Western culture. Many of these youngsters initiate year-round training and specialization in their sports at a very early age. This is probably due to the 'catch them young' philosophy, and to the belief that, to achieve international standing in later sporting life, intensive training should be started before puberty [1]. It is not uncommon, for example, for preteens to train 20 or more hours each week at regional training centers in tennis or gymnastics, to compete in triathlons, or for youngsters as young as 6-8 years of age to play organized hockey or soccer and travel with select teams to other towns and communities to compete against other teams of similar caliber.

The first volume of our work on the epidemiology of sports injuries in children dealt with individual sports. Organized team sport has become a feature of sports participation in Western children and adolescents, and, especially at school level, more than one team sport may well be practiced on a regular basis. This second volume concentrates on team sports. In this introductory article, we shall reiterate and expand on the general concepts on sports participation in young athletes already outlined in the first volume, and shall highlight some of the peculiarities of participation in team sports. 


\section{Peculiarities of Participation in Team Sports}

In team sports one cannot consider the athletes in and by themselves, but only as part of a team. Hence, individuality may be lost. Also, the features of team sport are such that one does not compete against time, or to set a record expressed in weight, time, distance or height, but 'to win', and that victory is not necessarily dependent on the absolute number of points scored. Although some team sports are, theoretically, noncontact, in reality most of them involve some elements of contact with other players, and this influences the features of the injuries seen. The psychology of team-sport participants is also different: participants in team sports must be able to interact with the other members of the team, need to be able to sacrifice their skills and wishes for the greater good of the team, and may have to learn to renege on the prima donna role that they may feel they were born to play [2]. Finally, as many team sports involve the ability to be in the right place at the right time, the motor skills required are varied, and may well be different from what is required for individual sports.

\section{Injury and Growth}

Engaging in sports activities at a young age has numerous health benefits but also involves risk of injury. Indeed, the young athlete may be particularly vulnerable to sport injury due to the physical and physiological processes of growth. Injury risk factors unique to the growing athlete include: susceptibility to growth plate injury, the adolescent growth spurt, limited thermoregulatory capacity, and maturity-associated variation. Although problems do not ordinarily arise at normal levels of activity, the more frequent and intense training and competition of young athletes today may create conditions under which these risk factors may exert their influence.

\section{Susceptibility to Growth Plate Injury}

Growth plate injuries have no counterpart in adult life. Tolerance limits of the growth plate may be exceeded by the mechanical stress of acute injury or by the repetitive physical loading demanded by training regimens in team sports [3]. Physeal injuries can produce permanent injury to the cells in the zone of hypertrophy, resulting in growth disturbance. The resistance of growth plate cartilage to stress is low [4]. It is also more susceptible than articular cartilage to compression and shearing, and than adjacent bone to shear and tension. In addition, the growth plate may be $2-5$ times weaker than the surrounding fibrous tissue [5]. Therefore, when disruptive forces are applied to an extremity, failure may occur through the growth plate. 
Good epidemiological data on the incidence of physeal injuries in team sports are lacking. However, literature reviews on this topic reveal multiple published case reports and case series that attest to the occurrence of both acute and chronic growth plate injuries in children's team sports $[3,6,7]$. Reports of sport-related physeal injuries resulting in growth disturbance are also reviewed in these papers.

\section{The Adolescent Growth Spurt}

The adolescent growth spurt appears to be a time of heightened risk for sports injury. The susceptibility of the growth plate to injury appears to be especially pronounced during periods of rapid growth [8-17]. Research pertaining to the development of physeal cartilage in animals shows a decrease in physeal strength during pubescence [9]. The data on humans are consistent with these findings [10-12]. An increase in the rate of growth at the growth plate is accompanied by structural changes that result in a thicker and more fragile plate [10, 13]. In addition, bone mineralization may lag behind linear growth during the pubescent growth spurt, thus rendering the bone temporarily more porous and subject to injury $[14,15]$. Studies of the frequency of physeal and other injuries indicate an increased occurrence of fractures during pubescence [14-17], and a noteworthy association between peak height velocity and peak fracture rate [14].

Results from two injury studies involving gymnasts indicate that high injury risk gymnasts were characterized by advanced competitive levels and rapid growth [18], and the gymnasts between 10 and 14 years of age were significantly more likely to report wrist pain than those who were either above or below this age range [19]. However, both of these latter studies did not compare individual velocities with growth rate.

It is hypothesized that the susceptibility for a variety of musculoskeletal injuries increases during periods of rapid growth because there is an increase in musculoskeletal tightness about the joints, loss of flexibility, and enhanced environment for injury [20]. Longitudinal growth occurs initially in the long bones of the extremities and in the spinal column. The muscle-tendon units that span the bones elongate secondarily in response to bone growth. Thus, during the adolescent growth spurt, these muscle-tendon units may become dramatically tighter thus increasing the risk of both acute and chronic joint-related injury. However, this hypothesis remains controversial $[21,22]$ and the results of one recent study suggests no loss of flexibility during periods of rapid growth [21].

\section{Limited Thermoregulatory Capacity}

Exercising children do not adapt as effectively as adults when exposed to high temperature. This may affect their performance and well-being, and increase the risk for heat-related illness. The thermoregulatory short-comings of children relative to adults during heat and exercise have recently been reviewed [23]. 
- children gain heat faster from the environment by convection, conduction, and radiation than do adults as a result of their greater surface area-to-body mass ratio than adults;

- children also produce more metabolic heat per mass unit than adults during activities that include walking and running;

- $\quad$ sweating capacity is considerably lower in children than in adults, which reduces their ability to dissipate body heat by evaporation; and

- children acclimatize to exercise in hot weather at a slower rate than adults. Thus, children will generate more heat for a given activity, yet are less able to dissipate body heat particularly in a hot environment. As children frequently do not feel the urge to drink enough to replenish fluid loss either before or following exercise, they may experience increased risk of dehydration and heat illness [24].

\section{Maturity-Associated Variation}

Children of the same chronological age may vary considerably in biological maturity status, and individual differences in maturity status influence measures of growth and performance during childhood and adolescence [23]. For example, there are definite structural, functional, and performance advantages of early-maturity boys in sports requiring size, strength, and power. The fear is that unbalanced competition between early- and late-maturing boys in contact sports such as gridiron football and ice hockey contribute to at least some of the serious injuries in these sports. Although a noninvasive method for estimating maturity status as a basis for grouping young athletes has recently been proposed [25], classification for participation in youth sports continues to rely primarily on chronological age which may add yet another dimension of individual variation. For example, within a single age-group (e.g., 12 years of age), the child who is 12.9 years of age is likely taller, heavier and stronger than the child who is 12.0 years of age, even though both are classified as 12 years of age. Thus, when children are grouped by age, variation is associated with chronological age per se and also with differences in biological maturity [23].

\section{Concern for the Health and Safety of Young Athletes}

The increased sports involvement of children from an early age and continued through the years of growth, against a background of their apparent vulnerability to injury, gives rise to concern about the risk and severity and long-term effects of injury. Recent data suggest that the risk of pediatric sports injury is high and constitutes a significant public health burden. During 2000-2001, for example, there were an estimated 4.3 million nonfatal sports- and 
recreation-related injuries treated in US hospital emergency departments [26]. Injury rates for both sexes peaked around adolescence, and were highest for boys. Children 5-14 years of age accounted for nearly $40 \%$ of all sportsrelated injuries [27]. Since only the more serious injuries present to hospital emergency departments, these data reflect only part of the overall injury picture in children's and youth sports. Many more, albeit less severe, injuries are treated in other settings such as healthcare providers' offices and clinics.

Parents need to know about the risks of injuries in children's and youth sports and what they can do to help prevent injury [27]. Indeed, young athletes of all ages and everyone who works with them, whether they be parents, sports medicine personnel, sports governing bodies, or coaches, need to know answers to questions such as the followings: Is the risk of injury greater in some sport activities, or level of activity, than in others? What types of injuries are most common in a given sport? What is the average time lost from injury and what is the risk of permanent impairment? Are some children prone to sports injury? Are some physical, psychological, or sport-related factors associated with an increased risk of injury? Can injury be prevented, and, if so, how? How effective are the preventive measures presently implemented? These are all questions which sports medicine personnel and coaches should be prepared to respond to, and the information should be made readily available to them. Providing this information is an important objective of sports injury epidemiology research.

\section{Epidemiology of Sports Injuries in Children}

Sports injury epidemiology studies the distribution and determinants of varying rates of sports injuries for the purpose of identifying and implementing measures to prevent their development and spread [28]. The epidemiologist in sports medicine is concerned with quantifying injury occurrence (how much) with respect to who is affected by injury, where and when injuries occur, and what is their outcome, for the purpose of explaining why and how injuries occur and identifying strategies to control and prevent them. The study of the distribution of varying rates of injuries (i.e. who, where, when, what) is referred to as descriptive epidemiology. The study of the determinants of an exhibited distribution of varying rates of injuries (i.e. why and how) and the effectiveness of selected preventive measures is referred to as analytical epidemiology [28].

The epidemiology of sports injuries in children and youth is an important area of research that has been largely overlooked in the medicine and sport science literature. It deserves serious study, particularly with regards to the identification and analysis of risk factors and preventive measures [29]. However, existing epidemiological research on pediatric sports injuries has 
already resulted in rule changes, new equipment standards, improved coaching techniques, and better conditioning of athletes [29]. For example, the prohibition of 'spearing' in football, and rules regarding water depth and the racing dive in swimming are examples of how data on deaths and catastrophic injuries can be used to help promote the safety of young athletes. Other preventive measures supported by research include anchoring movable soccer goals to prevent tipping, improved training for high school wrestling coaches, increased awareness of pathogenic weight control in wrestling and gymnastics, use of face shields when batting in baseball, and use of full face shields and rules against pushing or checking from behind in hockey [30].

\section{Purpose and Organization of this Book}

The benefits of physical activity for children and youth are substantial. However, growth in sports participation has contributed to an increase in pediatric sports-related injuries. In addition to the immediate healthcare costs, these injuries may have long-term consequences on the musculoskeletal system, resulting in limb dysfunction and a subsequent reduction in levels of physical activity [31]. However, half of all organized sports-related injuries among children can be prevented [32].

The purpose of Epidemiology of Pediatric Sports Injuries: Team Sports is to review comprehensively what is known about the distribution and determinants of injury rates in a variety of team sports, and to suggest injury prevention measures and guidelines for further research. This book provides the first comprehensive compilation and critical analysis of epidemiological data over children's team sports: baseball, basketball, gridiron football, ice hockey, rugby, and soccer. The previous volume (Epidemiology of Pediatric Sports Injuries: Individual Sports) in Medicine and Sport Science had addressed the epidemiology of injuries in pediatric individual sports.

A common, uniform strategy and evidence-based approach to organizing and interpreting the literature is used in the chapters of both volumes. All the sports-specific chapters are laid out with the same basic headings, so that it is easy for the reader to find common information across chapters. Section headings include, besides the Abstracts and Introductions:

- Incidence of Injury

- Injury Characteristics

- Injury Severity

- Injury Risk Factors

- Suggestions for Injury Prevention

- Suggestions for Further Research 
In each sport-specific chapter, an epidemiological picture has been systematically developed from the data available in prospective cohort, retrospective cohort, case-control, and cross-sectional studies (i.e. denominator-based designs). From this picture, it became possible to suggest preventive measures which seemed at least reasonable, given the level of evidence available, and to suggest needed areas for further research. A chapter titled 'Injury Prevention and Future Research' that addresses individual and team sports is included at the end of both volumes to provide a more global, across-sport examination of the literature identifying risk factors and prevention strategies for injury in child and adolescent sports.

Sport scientists and healthcare professionals will find Epidemiology of Pediatric Sports Injuries - both Vol. 48: Individual Sports and Vol. 49: Team Sports - useful in identifying problem areas in which appropriate preventive measures can be initiated to reduce the risk and severity of injuries. They will also want to use these volumes as a resource for research initiatives in the epidemiology of children's sports injuries. Sports administrators and coaches will find these books a thought-provoking reference that spurs discussion and encourages changes in the rules, equipment standards, coaching techniques, and athlete conditioning programs they use. Finally, these volumes will provide these individuals with current information on the epidemiology of pediatric sports injuries so that they, in turn, can inform parents about the risks of injury in children's sports and how they can help their children avoid or limit these risks.

\section{References}

1 Maffulli N: Children in sport: Questions and controversies; in Maffulli N (ed): Color Atlas and Text of Sports Medicine in Childhood and Adolescence. London, Mosby-Wolfe, 1995, pp 7-14.

2 Pensgaard AM, Roberts GC: The relationship between motivational climate, perceived ability and sources of distress among elite athletes. J Sports Sci 2000;18:191-200.

3 Caine DJ: Growth plate injury and bone growth: An update. Ped Exerc Sci 1990;2:209-229.

4 Micheli LJ: Pediatric and adolescent sports injury: Recent trends; in Pandolf KP (ed): Exercise and Sport Science Reviews. New York, Macmillan, 1986, pp 359-374.

5 Larson RL, McMahon RO: The epiphyses and the childhood athlete. JAMA 1966;196:607-612.

6 Caine DJ, Lindner K: Growth plate injury: A threat to young distance runners? Phys Sportsmed 1984;12:118-124.

7 Caine D: Injury and growth; in Sands WA, Caine DJ, Borms J (eds): Scientific Aspects of Women's Gymnastics. Med Sport Sci. Basel, Karger, 2003, vol 45, pp 46-71.

8 Ogden JA: Skeletal Injury in the Child. New York, Springer, 2000.

9 Bright RW, Burstein AH, Elmore SM: Epiphyseal-plate cartilage: A biomechanical and histological analysis of failure modes. J Bone Jt Surg (Am) 1974;56:688-703.

10 Alexander CJ: Effect of growth rate on the strength of the growth plate-shaft function. Skeletal Radiol 1976;1:67-76.

11 Morsher E: Strength and morphology of growth cartilage under hormonal influence of puberty. Reconstr Surg Traumatol 1968;10:1-96.

12 Speer DP, Braun JK: The biomechanical basis of growth plate injuries. Phys Sportsmed 1985; $13: 72-78$. 
13 Aldridge MJ: Overuse injuries of the distal radial growth epiphysis; in Hoshizaki BT, Salmela JH, Petiot B (eds): Diagnostics, Treatment and Analysis of Gymnastic Talent. Montreal, Sports Psyche Editions, 1987, pp 25-30.

14 Bailey DA, Wedge JH, McCulloch RG, Martin AD, Bernardson SC: Epidemiology of fractures of the distal end of the radius in children as associated with growth. J Bone Jt Surg [Am] 1989;71: 1225-1231.

15 Bradford DS: Vertebral osteochondrosis (Scheuermann's kyphosis). Clin Orthop 1981;158:83-90.

16 Peterson CA, Peterson HA: Analysis of the incidence of injuries to the epiphyseal growth plate. J Trauma 1972;12:275-281.

17 Benton JW: Epiphyseal fracture in sports. Phys Sportsmed 1982;10:63-71.

18 Caine D, Cochrane B, Caine C, Zemper E: An epidemiological investigation of injuries affecting young competitive female gymnasts. Am J Sports Med 1989;17:811-820.

19 DiFiori JP, Puffer JC, Aish B, Dorey F: Wrist pain in young gymnasts: Frequency and effects on training over 1 year. Clin J Sport Med 2002;12:348-353.

20 Micheli LJ: Overuse injuries in children's sports. The growth factor. Orthop Clin North Am 1983;14:337-360.

21 Feldman D, Shrier I, Rossignol M, Abenhaim L: Adolescent growth is not associated with changes in flexibility. Clin J Sport Med 1999;9:24-29.

22 Micheli LJ: Is adolescent growth associated with changes in flexibility. Clin J Sport Med 2000;10:76.

23 Malina RM, Bouchard C, Bar-Or O: Growth, Maturation, and Physical Activity (ed2), Human Kinetics, 2004, pp 267-273.

24 Walker SM, Casa DJ, Levrealt ML, Psathas E, Sparrow SL, Decher DR: Children participating in summer sports camps are chronically dehydrated. Med Sci Sports Exerc 2004;36(suppl 5): S180-S181.

25 Mirwald RL, Baxter-Jones ADG, Bailey DA, Beunen GP: An assessment of maturity from anthropometric measurements. Med Sci Sports Exerc 2002;34:689-694.

26 Centers for Disease Control and Prevention Morbidity and Mortality Weekly Report: Non-fatal sports- and recreation-related injuries treated in emergency departments, United States, July 2000-June 2001. MMWR Weekly 2002;51(33):736-740. Available from URL: http:// www.cdc.gov/mmwr/preview/mmwrhtml/mm5133a2.htm [Accessed on July 31, 2004].

27 National Safe Kids Campaign: Get into the game: A national survey of parents' knowledge, attitudes and self-reported behaviors concerning sports safety. Press Release, May 4, 2000. Available from URL: http://www.safekids.org/[Accessed on July 31, 2004].

28 Caine C, Caine D, Lindner K: The epidemiologic approach; in Caine D, Caine C, Lindner K (eds): Epidemiology of Sports Injuries. Champaign, Human Kinetics, 1996, pp 1-13.

29 Mueller F, Blyth C: Epidemiology of injuries in children. Clin Sports Med 1982;1:343-352.

30 Cantu RC, Mueller FO: Fatalities and catastrophic injuries in high school and college sports, 1982-97. Phys Sportsmed 1999;27:35.

31 Arendt EA: Specific injury locations - Overview; in Garrett WE, Lester GE, McGown J, Kirkendall DT (eds): Women's Health in Sports and Exercise. Rosemont, American Academy of Orthopedic Surgeons, 2001, pp 85-86.

32 National Safe Kids Campaign: Injury Facts. Available from URL: http://www.safekids.org/[Accessed on July 31, 2004].

Nicola Maffulli, MD, MS, PhD, FRCS (Orth)

Department of Trauma and Orthopedic Surgery

Keele University School of Medicine

Stoke on Trent ST4 7QB (UK)

Tel. +44 1782554 999, Fax +44 1782412 236, E-Mail n.maffulli@keele.ac.uk 